and $35 \%$ for more than 15 years. Consensus was reached on the description of a respirator incident $(72.5 \%)$, on handling of an incident concerning duration; short- (73.9\%), long- $(79.7 \%)$, mild- $(84.1 \%)$ and intense stimulation $(84.0 \%)$ as well as on the presentation of an incident; isolated- (72.5\%), clustered(76.8\%) or persistent incident (84.1\%).

Conclusions Implementation of the descriptions formulated in this study could lead to a more common language among professionals in the care of the preterm infant suffering from respiratory insufficiency. Professionals speaking the same language will result in a better quality of care.

\section{0-151 ATTITUDES OF MOTHERS ABOUT MEDICATION SAFETY OF CHIDREN}

${ }^{1} \mathrm{M}$ Uzun, ${ }^{2} \mathrm{G}$ Sahin, ${ }^{2} \mathrm{~S}$ Özcan, ${ }^{3} \mathrm{E}$ Gülsuyu, ${ }^{3} \mathrm{~F}$ Pars, ${ }^{4} \mathrm{~S}$ Atak, ${ }^{5} \mathrm{~S}$ Ekici. ${ }^{1}$ Child Health and IIlnesses Nursing, Bulent Ecevit University, Zonguldak, Turkey; ${ }^{2}$ Nursing, Fatih Sultan Mehmet Educatinal and Research Hospital, Istanbul, Turkey; ${ }^{3}$ Nursing, Lütfü Kirdar Educatinal and Research Hospital, Istanbul, Turkey; ${ }^{4}$ Nursing, Anadolu Health Center, Istanbul, Turkey; ${ }^{5}$ Nursing, Dokuz Eylül University Educatinal and Research Hospital, Istanbul, Turkey

\subsection{6/archdischild-2014-307384.218}

Background and aims Unintentional medication misuse can lead harm and additional healthcare costs. Children are vulnerable to mistakes in taking medications. Parents and caregivers administering medications can easily be confused by different instructions for use based on the child's age, weight, and other medical conditions. The aim of the study is to determine mother attitudes about medication safety of chidren.

Methods A descriptive quantitative approach was used in study. The data were obtained from 396 mothers at outpatient children clinic, by socio-demographic properties and medication safety questionnaire which was designed by researcher. Data was evaluated using the descriptive statistics available in the Statistical Package for Social Sciences Software (SPSS 16.0).

Results Most of the mothers were $(46,4 \%)$ between 20-29, high-school graduate (30.3\%) and housewife (84.1\%). (77.0\%) of children didn't have a chronic illness but $(60,1 \%)$ followed up by a physician once a mounth. Mother attitudes about medication safety are; if the illness was known before (47.5\%) buy and use the medicines of previous experiences. If they recognised the illness firstly, use the prescribed medication (99\%). $(81,6 \%)$ gave up medication when side effects occur. (99.0\%) of them obey the medication dosage, $(96.5 \%)$ of them reported the ineffectiveness of medication to physician. Residual medicines thrown down $(74,5 \%)$ and if nessesary stored at high places $(85,6 \%)$. If they forgot to schedule of medication, they waited until the next dose (60\%).

Conclusion Most of the mothers pay attention and perform true attitude for medication safety.

\section{0-152 HEPARIN SOLUTION VS NORMAL SALINE FOR FLUSHING PERIPHERAL VENOUS CATHETERS IN CHILDREN. PRELIMINARY RESULTS OF A RCT}

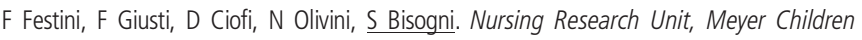
Hospital University of Florence, Florence, Italy

\subsection{6/archdischild-2014-307384.219}

Prolonging the duration of peripheral venous catheters (PVC) as long as possible in children is a nursing priority. However, available studies provide conflicting evidence on what kind of flush solution should be used to increase the life of PVCs in children.

Goal To compare the effectiveness of Normal Saline (NS) vs Heparin solution (HS) in maintaining the patency of PVCs in hospitalised children.

Methods Single blind randomised controlled trial. The study compares two solutions used to flush PVCs between an access and another: NS only (group A) vs a solution of Heparin $50 \mathrm{U} /$ $\mathrm{ml}$ in NS (HS) (group B). Subjects are children 2 to 14 with a G22 or G24 PVC, undergoing iv therapy twice-in-day, without coagulation problems and taking no immunosoppresant or steroidal drugs. Recruited subjects are randomised in either group using a randomization list. The sample numerosity was set at 26 per group. The outcomes evaluated are: PVC duration on site in hours; onset of complication.

Preliminary results. So far 18 children have been recruited ( 9 group A, 9 group B). The two groups do not differ statistically with regards to age, sex, location and number of access to PVC.

Mean duration of CVPs is $31.4 \mathrm{~h}$ in group A and $120.2 \mathrm{~h}$ in group $B(p=0.004)$. Complications have arisen in $88.9 \%$ of subjects in group A and $44.4 \%$ in group A ( $p=0.06)$.

Discussion Preliminary data show a relevant difference in PVCs flushed with HS. The study will continue until the numerosity of 52 subjects is reached.

\section{Nutrition and Neonatal}

\section{0-153 THE EFFECT OF AROMATHERAPY, MUSIC THERAPY AND VIBRATION APPLICATIONS ON NEONATAL STRESS AND BEHAVIOURS}

${ }^{1} \mathrm{O}$ Tosun, ${ }^{1} \mathrm{E}$ Erdem, ${ }^{2} \mathrm{~F}$ Elmali, ${ }^{3} \mathrm{~S}$ Kurtoglu. ${ }^{1}$ Nursing, Erciyes University Faculty of Health Sciences, Kayseri, Turkey; ${ }^{2}$ Biostatistics and Medical Informatics, Erciyes University Faculty of Medicine, Kayseri, Turkey; ${ }^{3}$ Paediatrics, Ercives University Faculty of Medicine, Kayseri, Turkey

\subsection{6/archdischild-2014-307384.220}

Background and aims It is important for physicians and nurses at neonatal units using advanced technology to understand neonatal behaviours and to support newborns by complementary care applications. This randomised controlled study was conducted experimentally to determine the effect of aromatherapy (with lavender+sweet almond oil), music therapy (Traditional Turkish Music) and vibration application (with electric toothbrush) on neonatal stress and behaviours.

Methods The study was conducted in a university hospital in Kayseri, Turkey. Totally 80 preterm infants assigned randomly to 4 groups as control, aromatherapy, music therapy and vibration application. Data were collected with questionnaire form, Brazelton Newborn Behavioural Assessment Scale (BNBAS) and Newborn Stress Evaluation Form (NSEF). On the first, third and fifth days, BNBAS and NSEF were applied both pre- and postintervention application continued one session/day for five days. Data were analysed with two-way analysis of variance for the repeated measurements, Student-Newman-Keuls tests.

Results Of the preterm infants, there was significant difference between measurement times in mean BNBAS scores $(p<0.001)$ and between measurement times $(p=0.003)$, group-time interactions $(\mathrm{p}<0.001)$ and between groups $(\mathrm{p}=0.040)$ in mean NSEF scores. Mean of differences between pre- and post-intervention of BNBAS and NSEF scores of complementary care 
application groups were higher than control group $(\mathrm{p}=0.001$, $\mathrm{p}=0.040)$ and the source of the difference was the control group.

Conclusions Aromatherapy, music therapy and vibration application decreased stress in newborns and favourably affected the behaviours of newborns. Complementary care applications (especially aromatherapy, music therapy) by physicians and nurses in neonatal units may be recommended.

\section{0-154 SUPPORTING EARLY BREAST MILK EXPRESSION IN THE NEONATAL UNIT - ARE WE DOING ENOUGH?}

${ }^{1} \mathrm{~V}$ Oliveira, ${ }^{2} \mathrm{~J}$ Angel, ${ }^{2} \mathrm{~K}$ Tavener, ${ }^{2} \mathrm{~A}$ Hickey. ${ }^{1}$ Paediatric Research, Guy's and St. Thomas' NHS Foundation Trust, London, UK; ${ }^{2}$ Neonatal Unit, King's College Hospital, London, UK

\subsection{6/archdischild-2014-307384.221}

Background and aims When breastfeeding gets delayed, prompt breast-milk expression facilitates the establishment and maintenance of lactation. On neonatal units, the recommended UNICEF target of all mothers achieving early milk expression within $6 \mathrm{~h}$ of birth is often not achieved. For critically ill infants, breast milk is particularly beneficial due to its nutritional and immunological benefits. Nonetheless, clinical practices that positively affect timely initiation are poorly described. Our aim was to investigate these practices.

Methods A cross-sectional survey was performed on a tertiary neonatal unit to assess lactation and breastfeeding support provided to mothers of term and preterm infants. Anonymous questionnaires were distributed, between days 3-7 postpartum.

Results Of 79 participants, 53\% were advised about breast-milk antenatally. Overall, $90 \%$ of mothers were helped to handexpress but only $11 \%$ within $6 \mathrm{~h}$ of birth. Breastfeeding nurses and midwives provided most advice but neonatal nurses were involved in only $10 \%$ of episodes. The likelihood of early expression was lower for mothers of preterm infants and in mothers who had not done kangaroo care but not significantly. Maternal perception of support was positive in $90 \%$ of cases.

Conclusion The survey demonstrated a large discrepancy between recommended levels of support and actual practice. Questions about the feasibility of UNICEF recommendations in neonatal units remain. Further analysis of the factors that impeded early expression is needed. It may well be that in mothers whose infants require neonatal care, there are entirely valid reasons for some delay in initiation of expression.

\section{Parent Satisfaction and Quality of Life}

\section{0-155 "GETTING ON" AND "FITTING IN": CHILDREN'S EXPERIENCES OF GROWING UP WITH CHRONIC ILLNESS IN ENGLAND, AUSTRALIA AND NEW ZEALAND}

${ }^{1} \mathrm{~B}$ Carter, ${ }^{2} \mathrm{~A}$ Dickinson, ${ }^{3} \mathrm{~K}$ Ford, ${ }^{4} \mathrm{~L}$ Bray, ${ }^{1} \mathrm{~J}$ Arnott, ${ }^{2} \mathrm{~T}$ Water, ${ }^{5} \mathrm{~K}$ Sanson, ${ }^{6} \mathrm{C}$ Tichanow. ${ }^{1}$ School of Health, University of Central Lancashire, Preston, UK; ${ }^{2}$ School of Health Care Practice, Auckland University of Technology, Auckland, New Zealand; ${ }^{3}$ University of Tasmania, School of Health Sciences, Hobart, Australia; ${ }^{4}$ Evidence-Based Practice Research Centre, Edge Hill University, Ormskirk, UK; ${ }^{5}$ Paediatrics, Starship Children's Health, Auckland, New Zealand; ${ }^{6}$ Paediatrics, Royal Hobart Hospital, Hobart, Australia

\subsection{6/archdischild-2014-307384.222}

Background and aims Chronic illness can require children to have complex treatments/interventions; these can affect their everyday lives. Traditionally, studies have focused on proxy- based, quantitative measures of impact on older children/adolescents. Few studies have used participatory methods with children across illness types and cultures.

This study explored children's understandings of their illness, the meanings they make and how their lives are affected by their experiences of chronic illness in England, Australia and New Zealand.

Methods The study adopted a qualitative, participatory methodology using photo-elicitation (photos and interviews) to build inductively derived knowledge grounded in the children's experiences. Forty-five children (6-12 years) from different diagnostic groups were recruited from hospital-based and support group settings in England, Australia and New Zealand. They used digital cameras to record aspects of their lives and chronic illness and their photos then guided audio-recorded interviews.

Results Results across the three countries show similarities in the ways in which the children create meaning about their illness and the strategies they use to be 'like other children'. Thematic analysis identified two key themes: 'getting on, negotiating risks and benefits' and 'fitting in'. Although most children did not hide their illness from their peers, they 'didn't talk much about it'. The meaning associated with their illness shifts in response to changes in physiology and life course.

Conclusions Using photo-elicitation promotes access to children's experiences by creating opportunities for them to talk of how they perceive, understand and manage their symptoms and experience their everyday lives.

\section{0-156 THE EXPERIENCES OF MOTHERS WHO HAVE CHILDREN WITH CEREBRAL PALSY: A QUALITATIVE STUDY}

${ }^{1} \mathrm{M}$ Kurtuncu, ${ }^{2} \mathrm{~L}$ Utas Akhan, ${ }^{3} \mathrm{H}$ Yildiz, ${ }^{4} \mathrm{~B}$ Demirbag. ${ }^{1}$ Pediatric Nursing, Bulent Ecevit University, Zonguldak, Turkey; ${ }^{2}$ Psychiatric Nursing, Bulent Ecevit University, Zonguldak, Turkey; ${ }^{3}$ Nursing, Uludag University, Zonguldak, Turkey; ${ }^{4}$ Nursing, Karadeniz Technical University, Zonguldak, Turkey

\subsection{6/archdischild-2014-307384.223}

Background and aims The purpose of this study is to determine the difficulties experienced by mothers of children with cerebral palsy and their needs.

Methods Qualitative design. The study was conducted in the province of Zonguldak, Turkey, at a special rehabilitation centre with 15 children with $\mathrm{CP}$ and their mothers registered at the centre. An in-depth interview was held with each of the mothers consenting to participate in the study.

Results The subjects' sociodemographic characteristics shows that mean age is $37.06 \pm 1.23$ years, most are elementary school-middle school graduates, city-dwellers and $73.3 \%$ have no chronic disease. All of the women having children with $\mathrm{CP}$ said that they were shocked when they first found out about the diagnosis, that they suffered disappointment, were very frightened because they knew nothing about the disease and also guilty for bringing such a child into the world. It was seen however that fathers had difficulty accepting their child's sickness but that mothers acknowledged this fact sooner than their spouses. All of the mothers stated that they could not find a suitable institution to place the child and that teachers at school were inadequate in terms of the child's education and that they would not pay them the attention they needed.

Conclusions The families with children diagnosed with cerebral palsy, couples are faced with many difficulties that include personal relations, social and economic problems, as well as issues involving the sick child's care and education. In connexion with 